SEÇ̃̃O TEMÁTICA:

CAPITALISMO, ESTADO E EDUCAÇÃO:

OS LIMITES DO CAPITAL

\title{
Capitalismo, Classe e Meritocracia: um estudo transnacional entre o Reino Unido e o Brasil
}

\author{
Michael Wayne' \\ Vinícius Neves de Cabral"
}

'Universidade de Brunel, Londres - Reino Unido

"Universidade Estadual de Londrina (UEL), Londrina/PR - Brasil

RESUMO - Capitalismo, Classe e Meritocracia: um estudo transnacional entre o Reino Unido e o Brasil. A partir das bases teóricas do marxismo, este ensaio concentra-se na análise dos papéis desempenhados pela meritocracia no sistema capitalista e seus impactos sobre a classe trabalhadora. Este estudo transnacional discute os aspectos econômicos, ideológicos, culturais e políticos da meritocracia no Reino Unido e no Brasil. Em resumo, nossas análises apontam na direção do que nós chamamos de 'uma estrutura de valores, de práticas, de significados e de símbolos meritocráticos'. Ao reproduzir as relações capitalistas de poder e classe, a meritocracia funciona como um pilar ideológico da hegemonia do capitalismo e uma justificativa para as desigualdades que ele mesmo engendra.

Palavras-chave: Marxismo. Meritocracia. Desigualdades. Neoliberalismo. Individualismo.

ABSTRACT - Capitalism, Class and Meritocracy: a cross-national study between the UK and Brazil. Drawing on a Marxist theoretical framework, this essay concentrates on the analysis of the roles played by meritocracy in the capitalist system and its impacts on the working classes. This crossnational study discusses economic, ideological, cultural, and political aspects of meritocracy in the United Kingdom and in Brazil. In summary, our analyses indicate towards what we may call 'a framework of meritocratic values, practices, meanings, and symbols'. Reproducing capitalist relations of power and class, meritocracy functions as an ideological pillar of capitalism's hegemony and a justification to the inequalities it engenders. Keywords: Marxism. Meritocracy. Inequalities. Neoliberalism. Individualism.

Educação \& Realidade, Porto Alegre, v. 46, n. 3, e117535, 2021. 
Capitalismo, Classe e Meritocracia

\section{Introdução}

Neste ensaio, pretendemos apresentar um estudo transnacional sobre a ascensão e o impacto da meritocracia no Reino Unido (UK) e no Brasil. Apesar das especificidades nacionais, apresentamos uma análise comparativa internacional entre os dois países para demonstrar a centralidade da meritocracia para o capitalismo contemporâneo. A meritocracia é uma ideologia que reforça as desigualdades econômicas, sociais e históricas, ao mesmo tempo em que oferece a promessa de uma saída para essas desigualdades. Ela individualiza os problemas estruturais, atribui responsabilidade de resultados aos indivíduos e torna essas estruturas invisíveis à crítica popular e às reformas políticas.

A meritocracia endossa a imagem de que, no capitalismo, “[...] os indivíduos progridem e são recompensados na proporção direta de seus esforços e habilidades individuais" (McNamee; Miller, 2009, p. 2). A meritocracia, portanto, reproduz a promessa de que o mérito individual é a chave para alcançar o que o capitalismo chama de sucesso. Ela funciona como um sistema de justificação das desigualdades engendradas no cerne das relações de poder e classe do capital (Littler, 2018a).

Na estrutura ideológica do capitalismo, a meritocracia impinge nos indivíduos a crença de que uma combinação de certas características - o talento, a atitude certa e o trabalho árduo - coloca alguns indivíduos no topo da estrutura de classes e isso lhes dá o direito de governar sobre os outros (McNamee; Miller, 2009). Ao mesmo tempo em que esse sistema meritocrático supostamente valoriza essas características especiais, ele blinda suas contradições inerentes para a população em geral. Como McNamee e Miller (2009) apontam, a meritocracia ignora os papéis desempenhados pela herança, pelas conexões, pela sorte, pela discriminação, pelo casamento e pela criminalidade no caminho para o sucesso.

No Reino Unido, a ascensão do neoliberalismo e do thatcherismo na década de 1980 foi o cenário ideal para expandir e cimentar práticas meritocráticas (Harvey, 2005). Thatcher conseguiu vincular “[...] a emancipação e a mobilidade social à aquisição de bens de consumo, à casa própria e à privatização dos serviços públicos e dos programas sociais de habitação" (Littler, 2018b, p. 4). Anos depois, o liberalismo social promovido pela ideologia política do ex-primeiro-ministro Tony Blair foi usado como meio de ampliação dos valores meritocráticos para grupos anteriormente excluídos (Littler, 2018a; 2018b). A ascensão da meritocracia esteve intimamente associada ao desmantelamento cuidadoso e lento do Estado de bem-estar social britânico, à medida que a provisão coletiva foi substituída pela promessa de mobilidade individual. No Brasil, o estabelecimento de um Estado de bem-estar social e promoção da mobilidade estrutural, durante os governos do PT (Partido dos Trabalhadores), ameaçou os privilégios consolidados da elite. No caso do Brasil, uma furiosa reação da direita mobilizou a ideologia da meritocracia para defender os privilégios históricos. Em ambos os contextos, a meritocracia foi promovida por meio de instituições culturais, midiáti- 
cas e educacionais, em outras palavras, por meio do cultivo cuidadoso de uma subjetividade desligada da consciência das condições materiais de existência, que são o principal determinante nos resultados individuais e nas oportunidades de vida.

Agora passamos para uma análise mais detalhada de cada estudo de caso. Iniciamos a discussão pelo estudo de caso britânico e depois o brasileiro.

\section{O Novo Trabalhismo, Cultura e Meritocracia}

$\mathrm{O}$ etos da meritocracia de (i) liberdade individual, de (ii) frutos justos do trabalho árduo e dos (iii) talentos e a ideia de mobilidade social alheia às origens de classe triunfando sobre as barreiras sociais foi fundamental para a marca de Conservadorismo de Margaret Thatcher, nos anos 1980, e para a marca do Liberalismo Social de Tony Blair durante o período dos governos do Novo Trabalhismo entre 1997 e 2010. Esses são repertórios distintos do neoliberalismo, o primeiro investiu em um nacionalismo fortemente excludente nas questões étnicas e no consumismo, o último se promoveu como uma política mais inclusiva, multicultural e, portanto, mais autenticamente meritocrática (Littler, 2018a, p. 87). Não é surpresa, então, que Blair trouxe a meritocracia e as indústrias culturais para o centro do discurso político do Novo Trabalhismo.

Se a indústria alguma vez constituiu uma base social significativa de apoio ao Labour (Partido Trabalhista Britânico), ligando-o à classe trabalhadora, a desindustrialização, especialmente no norte da Inglaterra e na Escócia, esgotou as conexões políticas e econômicas entre o partido e as tradicionais orientações de classe. As indústrias culturais viabilizaram ao Novo Trabalhismo a manutenção de um compromisso com pelo menos uma reduzida base da manufatura, enquanto proporcionava um deslumbramento nas relações públicas do discurso político centrado na promoção da Nova Grã-Bretanha nos mercados internacionais de imagem (cinema, televisão, publicidade, música etc.). Se o Labour antes colocava a classe trabalhadora no centro de sua visão éticopolítica, sua agência preferida de história era agora um pouco diferente: um minúsculo estrato de classe média alta de talento e de executivos (Wayne, 2018, p. 174-80).

Tomou-se como pressuposto que o favorecimento das prioridades econômicas capitalistas convencionais não seria contraditório em relação às oportunidades para todos das ambições de justiça social do Novo Trabalhismo. Em geral, para o Novo Trabalhismo o principal inimigo contra a oportunidade não era o tipo de desigualdade de classe social associada ao capitalismo, mas os alvos favoritos do Liberalismo Social associados ao conservadorismo, como o privilégio, o esnobismo, a intolerância, a falta de mente aberta e a falta de alternativas educacionais para o autoaperfeiçoamento. "Não peço desculpas", escreveu Blair, "por querer que a Grã-Bretanha seja uma nação caracterizada pelo mérito, não pelo privilégio ou pelo conservadorismo” (Blair, T., 2001, p. 55). 
Uma guerra contra o conservadorismo (as noções antiquadas de decoro da classe média alta) não exigia uma crítica, muito menos um ataque, à economia política do capitalismo tardio.

Uma vez que a palavra cultura ainda retinha conotações que transcendiam a prioridade do valor de troca, ela era frequentemente associada ou substituída no discurso do Novo Trabalhismo pela palavra criatividade. Blair, mais uma vez: "O próximo século será dominado pelo cérebro, não pela foça bruta. Criatividade e conhecimento serão as ferramentas-chave. E a Grã-Bretanha sempre foi um líder mundial em criatividade e inovação" (Blair, T., 2001, p. 53). Como Toby Miller observou, o conceito de criatividade desloca o foco do realmente é produzido para o processo e para os inputs, uma "[...] mudança bizarra no significado adjetival [que] caracteriza qualquer coisa que faça dinheiro como algo criativo" (Miller, 2009, p. 95, grifo nosso). Assim, as indústrias criativas foram cada vez mais reconhecidas, por responsáveis pela elaboração de políticas públicas e think tanks, como o "[...] plano para uma nova forma de economia pós-industrial” (O’Brien; Laurison; Miles; Friedman, 2016, p. 117). Os mercados de trabalho altamente flexíveis nas indústrias cinematográficas dos EUA e do Reino Unido, por exemplo, foram vistos como indicadores do caminho para o futuro dos empregos precários (ver Helen Blair, 2001), mas que deveriam ser incorporados por seus pontos positivos.

Essas táticas e discursos políticos re-empacotaram a instabilidade da carreira (o fim de um emprego para toda a vida) como parte de um contexto empolgante e dinâmico em que os trabalhadores embarcariam em carreiras de portfólio e em qualquer carreira e viveriam de sua própria perspicácia, assumindo riscos como freelancers e pulando de projeto em projeto. As realidades da instabilidade no trabalho podem ser disfarçadas ao incutir nesta economia política cuidadosamente construída, fundada na diminuição radical do poder sindical por meio de mudanças nas práticas de trabalho e restrições legais, um tom moral e cultural extraído das narrativas românticas de rebelião associadas à vida boêmia do artista que insistia em autonomia, autenticidade, autoexpressividade e um libertarianismo geral (McGuigan, 2009; Ross, 2010; Boltanski; Chiapello, 2018).

No final do período do Novo Trabalhismo, em 2010, as análises acadêmicas apresentaram uma realidade menos cor-de-rosa sobre as condições de trabalho do trabalhador cultural do que os responsáveis por políticas públicas e os think tanks da nova economia defendiam (Banks; Hesmondhalgh, 2009). A ênfase na autossuficiência, na ambição, na competição e no suposto talento em detrimento da proteção do trabalho e dos direitos trabalhistas disfarçou a exploração, a autoexploração (uma vez que os trabalhadores voluntariamente trabalham em excesso porque são apaixonados pelo trabalho) e o subemprego (McRobbie, 2011, p. 41; Blair, H., 2001). Manter uma carreira tornou-se algo muito mais difícil para os verdadeiros criativos, que foram paralisados pela redução dos salários e pelas condições estressantes do trabalho casual, do que para aqueles mais funcionais, cortando custos e tomando 
Wayne; Cabral

decisões de emprego (McGuigan, 2010, p. 330). A esperança de que as indústrias criativas pudessem impulsionar o crescimento econômico regional e resolver uma ampla gama de outros problemas sociais procuravam se sustentar em uma lacuna que crescia continuamente entre a retórica e as evidências (Oakley, 2011; Belfiore, 2009). Enquanto isso, a noção de que as próprias indústrias culturais eram exemplos de mobilidade social foi contestada pela sub-representação de mulheres, minorias étnicas e da classe trabalhadora na força de trabalho em geral, bem como em cargos de tomada de decisão sênior (Oakley, 2011; Littler 2018a, p. 161). Por exemplo, em termos de representação, Friedman e Laurison (2019) descobriram que, no cinema e na televisão, a força de trabalho geral tinha cerca de metade da proporção de pessoas da classe trabalhadora em comparação à força de trabalho como um todo. Os empregos de engenharia ou cargos sênior nos serviços de emergência (polícia, bombeiros e serviços de resgate, e serviços de emergências médicas) se saíram significativamente melhor em representação proporcional da classe trabalhadora do que a muito mais alardeada indústria cultural (Friedman; Laurison, 2019, p. 33).

\section{Neoliberalismo e a Era da Austeridade}

Após a crise global de 2008, o Novo Trabalhismo perdeu seu brilho ideológico, mas a gama limitada de possibilidades políticas alternativas ficou muito evidente quando um novo governo de Coalizão Conservador-Liberal formou o poder entre 2010 e 2015, seguido por sucessivos governos conservadores (2015-2017, 2017-2019, 2019 até o presente). Este período foi testemunha do surgimento da austeridade como a resposta política e de política pública à crise econômica. Isso significou cortes substanciais nos serviços públicos e para as autoridades municipais locais (Blackburn, 2018, p. 9). Uma das primeiras coisas que o governo conservador-liberal fez foi aproveitar as taxas individualizadas para alunos do ensino superior, que havia sido introduzida pelo Novo Trabalhismo, aumentando os custos para cerca de $£ 9.000$ por ano. A expansão dos programas em mídia, cinema, televisão, cultura e artes com o impulso do Novo Trabalhismo da economia criativa agora só poderia ser aproveitada com altos níveis de dívida pessoal (incluindo empréstimos de subsistência para os estudantes). Ao mesmo tempo, poucos meses após assumir o cargo, a Comprehensive Spending Review do governo da Coalizão, que priorizou os planos de redução do déficit, determinou cortes de $15 \%$ a $30 \%$ nas principais instituições culturais, como museus e galerias, o British Film Institute e o Arts Council (Newsinger, 2015, p. 306).

Nesse contexto de dificuldades crescentes, a condição de classe foi retomada pelos círculos acadêmicos e publicações populares. As indústrias culturais e, em particular, a profissão de ator no Reino Unido pareciam ser um para-raios para as preocupações sobre o impacto que a desigualdade estava tendo sobre algumas das acalentadas ilusões da meritocracia. Uma série de relatórios na imprensa popular destacou as

Educação \& Realidade, Porto Alegre, v. 46, n. 3, el17535, 2021. 
potenciais consequências para as artes cênicas devido às crescentes dificuldades enfrentadas pelos atores com origem na classe trabalhadora em sustentar carreiras no setor.

Entre 2015 e 2017, Wayne e a codiretora, Deirdre O’Neill, produziram um documentário, The Acting Class $^{1}$, sobre as questões de estratificação de classes na profissão de ator. $O$ filme baseou-se em entrevistas tanto com atores mais jovens da classe trabalhadora, lutando para entrar e permanecer na indústria, como com atores mais velhos, com carreira estabelecida e preocupados com a diminuição das oportunidades para a diversidade de classes na profissão. Como metodologia de pesquisa, entrevistas gravadas organizadas em um filme em torno de grupos temáticos têm duas vantagens sobre a pesquisa acadêmica escrita mais convencional. Em primeiro lugar, permite aos sujeitos da pesquisa articularem suas próprias reflexões sobre suas próprias experiências diretamente a um espectador. O que chama a atenção é a inteligência com que esses sujeitos falam de sua experiência, sobre as atitudes de discriminação de classe com que se depararam e às vezes internalizaram, e a força emocional transmitida ao público que assistia o porquê isso é importante como uma questão de justiça social. Em segundo lugar, o arranjo de vozes em agrupamentos temáticos é crucial para socializar a experiência, ou seja, ela aprofunda a situação em comum e os constrangimentos com os quais os indivíduos são confrontados. Isso é de fundamental importância porque na era do neoliberalismo e da meritocracia as condições sociais, as restrições estruturais, os problemas compartilhados são sempre individualizados e transformados em desafios e oportunidades: o primeiro é um problema contra o qual o valor moral do indivíduo pode ser testado, enquanto o último se refere às recompensas disponíveis para aqueles indivíduos talentosos o suficiente para superarem seus problemas. Esta é uma ideologia muito brutal, projetada para fazer as pessoas pensarem que, em última análise, são responsáveis pelos desdobramentos de suas vidas. Se seus sonhos não se tornam realidade, a ideologia da meritocracia os ensina que é porque eles não tiveram a força ou o talento para terem sucesso.

Existem três razões principais pelas quais a acessibilidade da profissão de ator a uma ampla gama de pessoas, em termos de classe, gênero e etnia, é importante.

1) As questões de justiça social: por que uma profissão deveria ser amplamente monopolizada por um determinado grupo, enquanto outros se encontram significativamente sub-representados dentro dele? A questão da diversidade de acesso às artes - como participantes e públicos - foi apropriadamente promovida pela política pública e pela agenda política. Contudo, como Randle et al. observam, “[...] frequentemente questão da classe social está ausente na agenda da diversidade" (Randle et al., 2008, p. 9). Isso significa que é improvável que o cada vez mais importante e determinante fator econômico, assim como as outras questões determinadas pela classe social que moldam o ingresso e o sucesso nas artes em geral e na profissão de ator especificamente, seja tratado de forma adequada. 
2) As questões econômicas para a indústria: uma composição excessivamente homogênea de talentos criativos provavelmente terá dificuldade para inovar e encontrar novos públicos e mercados. O relatório da Comissão Warwick concluiu que as crianças nascidas em famílias de baixa renda eram as menos propensas a encontrar empregos de sucesso nas indústrias culturais e criativas, no entanto, "[...] a diversidade é essencial para o futuro sucesso" dessas indústrias (Neelands et al., 2015, p. 14-15).

3) Estão em jogo questões mais amplas relacionadas à identidade nacional e à ideologia: as artes performativas (ou cênicas) contam histórias que projetam implicitamente imagens do coletivo, sua história, identidade, quem são, como são, como falam, o que valorizam, quem respeitam e assim por diante. Se a profissão de ator é construída por uma gama restrita de grupos sociais, se há oportunidades limitadas para a classe trabalhadora ou atores negros, por exemplo, isso provavelmente moldará os tipos de histórias que as indústrias culturais produzem e os ângulos a partir dos quais essas histórias serão contadas. As indústrias britânicas de cinema e televisão, por exemplo, há muito projetam uma certa identidade de herança aristocrática branca nos mercados internacionais de imagem, especialmente para o mercado americano (Wayne, 2006). O aumento das barreiras para os atores da classe trabalhadora apenas reforçará essa tendência histórica. A seguir, analisaremos algumas das múltiplas barreiras que inviabilizam a entrada e a manutenção das carreiras dos atores da classe trabalhadora. As questões de justiça social que essas barreiras levantam falam mais diretamente à questão da meritocracia e por que ela deve ser considerada principalmente como uma ideologia do liberalismo.

\section{Barreiras, Não Oportunidades}

The Acting Class começa com Tom Stocks, um jovem aspirante a ator de Bolton, no norte da Inglaterra, revisitando uma escola de atores em Londres chamada East 15. Foi ali que Stocks recebeu uma oferta para o curso de mestrado em artes cênicas. No entanto, as taxas anuais do curso eram de $£ 12.000$ e o custo de vida (em Londres) exigiria um adicional de $£ 6.000$ a $£ 9.000$ por ano. Tom já tinha uma dívida do curso de graduação, que ofereceu bem menos ênfase na prática profissional. Parado em frente à East 15, Tom diz que tentou economizar o dinheiro para o curso de um ano por mais de um ano e meio, enquanto trabalhava como cozinheiro com um salário-mínimo. Ele não conseguiu. Isso o estimulou a criar uma organização dedicada a ajudar atores da classe trabalhadora, com uma rede de apoio e oportunidades para participar de peças. A própria experiência de Tom, de ficar fora do curso, não era incomum. O filme também apresenta Amy, uma jovem da classe trabalhadora de Liverpool, que recebeu uma oferta de uma vaga em um curso básico em outra escola de teatro em Londres, a Italia Conti. Ela também tentou guardar o dinheiro por dois anos, mas no final teve que admitir a derrota: "Senti que fracassei porque não tinha dinheiro, não tinha mi- 
Capitalismo, Classe e Meritocracia

lhares e milhares e milhares de libras, para fazer aquele curso por um ano" (10.50).Conseguir uma oferta para frequentar uma escola de teatro é em si extremamente difícil. Isso normalmente exige vários testes em diferentes escolas em todo o país. Mas as escolas de teatro também cobram pelas próprias audições e algumas até cobram apenas pela inscrição na escola, então os custos logo aumentam (Labour Party, 2017, p. 11). Quando essas taxas são combinadas aos custos de viagem para diferentes locais do país, os atores de origem da classe trabalhadora enfrentam barreiras consideráveis apenas para ter acesso ao treinamento. Mas existem filtros econômicos mais substanciais que estratificam o acesso à educação e às rotas que a educação oferece para as profissões altamente valorizadas: o sistema de ensino privado do Reino Unido.

Um relatório da Comissão de Mobilidade Social e Pobreza Infantil concluiu que os $7 \%$ que estudaram em escolas privadas dominam desproporcionalmente os escalões mais elevados de profissões como do judiciário, da política e da mídia (2014, p. 12). A pesquisa da Sutton Trust fornece algumas evidências de que isso também pode ser identificado na profissão de ator. No cinema, $42 \%$ dos vencedores britânicos dos principais prêmios da British Academy Film and Television (BAFTA) frequentaram escolas privadas pagas (Kirby, 2016, p. 2). A escola particular mais famosa do país, Eton (que cobra cerca de $£ 35.000$ por ano) produziu muitos atores famosos, incluindo, recentemente, Dominic West (The Wire - 2002-2008, Pride - 2014, Les Misérables - 2018-19), Damian Lewis (Band of Brothers - 2001, Homeland-2011-14, Once Upon A Time In Hollywood - 2019) e Eddie Redmayne (The Good Shepherd-2006, Les Misérables - 2012, The Danish Girl-2015, Fantastic Beasts and Where to Find Them-2016, The Trial of the Chicago 7 -2020). Os três protagonistas do drama de espionagem da BBC The Night Manager (2016) - Tom Hiddleston (que mais tarde interpretaria Loki nos filmes Thor e Vingadores), Tom Hollander e Hugh Laurie - foram todos educados na mesma escola particular de educação infantil para meninos e meninas de Oxford, conhecida como The Dragon School. A escola também produziu atores como Emma Watson, Jack Davenport, Hugh Dancy, Dom Joly e Jack Whitehall (Ramaswamy, 2016). Além de treinamento, instalações, experiência e incentivo geral em suas ambições, as escolas privadas também fornecem capital social de alto valor, o networking fundamental, o conhecer as pessoas certas em posições importantes de tomada de decisão da indústria.

Em uma sociedade tão sensível às origens e diferenças de classe como o Reino Unido, a educação privada cimenta e apura um senso mais geral de diferença social que constrói uma barreira fundamental entre as pessoas com origem na classe trabalhadora e sua entrada e seu desenvolvimento em profissões dominadas pela elite. Com base em entrevistas e observação etnográfica, Friedman e Laurison exploraram como a correspondência cultural reproduz oportunidades e diminui a importância do talento. A correspondência cultural se sustenta na premissa de que similaridade gera conexão (Friedman; Laurison, 2019, p. 214). A conexão pode ser tão simples quanto ser ex-aluno das melhores 
universidades, como Oxford e Cambridge. Como diz o ator negro da classe trabalhadora, Elliot Barnes-Worrell:

\begin{abstract}
As pessoas no topo são todos homens brancos de classe média ou homens brancos de classe alta com educação privada. E então, quando eles querem contratar alguém para trabalhar para eles, eles se contratam entre eles. Eles dizem: 'você foi para Cambridge, eu fui para Cambridge, nós fomos para Cambridge, vamos todos ficar juntos' $(31,43)$.
\end{abstract}

Mas essa correspondência cultural também funciona de forma mais sutil por meio de uma ampla gama de signos culturais pelos quais os membros da mesma classe se reconhecem. Esses signos, como Bourdieu demonstrou, estão gravados no corpo e são veiculados por meio dele em todos os níveis, incluindo o comportamento, a vestimenta e a fala (Bourdieu, 2000, p. 118). A fala (speech) no Reino Unido é fortemente codificada pela classe, a received pronunciation (ou RP), o sotaque da classe média-alta, que apaga quaisquer especificidades regionais e cria uma pretensa universalidade sem lugar que é na verdade específica de uma classe. A RP desempenha um papel importante na profissão de ator no Reino Unido. Ela indica um fator de domínio da classe média em todo o panorama das artes cênicas que, como parte de sua formação na escola de teatro, os atores devem dominar. Mas vários atores da classe trabalhadora com quem conversamos notaram que isso às vezes era levado ainda mais longe nas escolas de teatro. Julie Hesmondhalgh:

Houve um momento no meu primeiro ano em que fui incentivada a falar em RP fora dos ensaios e fora da sala de aula, para que se tornasse para mim uma forma natural de falar. E eu não estava feliz com isso e não queria fazer isso e conheço algumas pessoas que passaram por isso [...]. Essa voz faz parte de quem eu sou e de onde venho [...]. Ela está muito ligada a quem eu sou, não vi necessidade de fingir ser uma pessoa diferente enquanto realizava minhas atividades diárias (26.25).

A validação cultural mais ampla da RP, e da identidade da classe média que ela expressa, significa que aqueles que crescem em uma classe diferente adquirem um sentimento de inferioridade e falta de confiança. A confiança é de fato um dos principais atributos da subjetividade da classe média. Mas essa confiança não deve ser confundida com ser superconfiante ou agressivo e mandão, ao contrário, é uma confiança nascida de um senso sutil de direito, de que o mundo está realmente lá para você ter sucesso (Friedman; Laurison, 2019, p. 23-27). $\mathrm{O}$ ator Christopher Eccleston trouxe à tona as implicações da hierarquia de valor atribuído aos sotaques em The Acting Class:

Uma coisa que foi muito poderosa para mim quando criança, sempre que ouvia uma voz de autoridade, sempre que ouvia uma voz que era 'intelectual', sempre que ouvia uma voz que era 'cultural', ela era branca, era masculina e era classe média. O dialeto é uma coisa importante. Se 
você fala como eu e milhões de outras pessoas como eu da Escócia ou de Liverpool ou qualquer outro lugar, você não necessariamente acha que seu sotaque denota criatividade ou intelecto. Então, você não acha que vai interpretar Hamlet. Você pensa que as propriedades de ser intelectual e poético e comovente residem em um sotaque RP (25.18).

A profissão de ator é uma das profissões mais precárias que existem para se tentar estabelecer uma carreira. Uma das razões para isso é que na economia neoliberal de exploração flexível de hoje, é muito raro ter um contrato de longo prazo (sendo a única exceção os seriados de longa duração em que os personagens se tornam um elemento fixo nos enredos). A maioria dos trabalhos de atuação é construída em torno de projetos de prazo relativamente curto. Nos primeiros anos, pode haver lacunas consideráveis entre os empregos. Atores de origem na classe média, no entanto, podem apelar para "[...] a dádiva intergeracional do capital, seja in vivo ou por meio de herança” (Friedman; O’Brien; Laurison, 2017, p. 1000). De forma mais coloquial, o primeiro é conhecido como o Banco da mamãe e do papai - uma forma de patrocínio financeiro que é particularmente importante no contexto precário dos trabalhos da elite no início de carreira, que fornecem suporte, segurança financeira para assumir riscos, desenvolver redes (como workshops contínuos com diretores de elenco) e não necessariamente ter que aceitar empregos que não estejam relacionados à área para pagar por itens essenciais, como aluguel e comida. Portanto, estar disponível para audições que geralmente chegam em um prazo muito curto. Esta rede de segurança privada permite aos privilegiados permanecerem neste setor altamente precário por mais tempo, esperando pelo prêmio do trabalho contínuo (Friedman e Laurison, 2019, p. 90). Em The Acting Class, Teddy Rose trouxe à tona as ansiedades existenciais mais profundas que essa falta de capital econômico e social (redes) tem para o ator da classe trabalhadora:

\begin{abstract}
Os atores da classe trabalhadora com quem estive, estudei, trabalhei e cresci, eles caem fora porque a cada ano que passa eles pensam 'ah, não, eu estou um ano mais velho', e o dinheiro começa a se tornar muito mais importante. Como atores da classe trabalhadora, se não conseguirmos, estamos ferrados. Nós comprometemos tudo o que temos em torno da possibilidade de nos tornarmos atores, não temos membros da família que poderiam nos fornecer um bom emprego se tudo der errado ou pessoas que conheçam alguém que conhece alguém que pode nos empregar se não der certo para nós. Então, eles podem tentar por alguns anos e, se tudo vai por água abaixo, eles ainda estarão empregados em outro lugar. Para nós, é o caso de: se não conseguirmos ser atores, e nós comprometemos tudo que tínhamos para nos tornarmos atores, não teremos nada em que nos apoiar. Não temos rede de segurança (18.40).
\end{abstract}

Os sociólogos chamam a filtragem gradual dos talentos da atuação da classe trabalhadora de leaky pipeline ${ }^{2}$ (Partido Trabalhista, 2017, 
p. 5). Embora conjuntos de dados completos que sejam representativos da composição de classes de atores no Reino Unido não estejam disponíveis, os sociólogos foram capazes de analisar pelo menos alguns dados de pesquisa. The Great British Class Survey (GBCS, 2013), uma pesquisa online de autoidentificação conduzida por acadêmicos da London School of Economics, em colaboração com a British Broadcasting Corporation, gerou dados sobre 402 atores. Enquanto a Labour Force Survey indica uma amostra muito menor de 61 atores. Sociólogos descobriram que apenas $10 \%$ dos atores do GBCS eram de origem da classe trabalhadora e apenas 16\% na Labour Force Survey (Friedman; O’Brien; Laurison, 2017, p. 997). Neste último, em termos de representação, novamente cerca de metade da proporção dos trabalhadores de classe trabalhadora da força de trabalho ativa do Reino Unido, de acordo com classificações sociológicas baseadas nas ocupações dos pais. Não há, então, nenhuma exceção mágica para as artes cênicas e as indústrias culturais em geral em relação às barreiras estruturais que reproduzem a desigualdade de classes no Reino Unido, independentemente da ideologia e dos discursos políticos em torno da meritocracia.

\section{Meritocracia e Classe Média Brasileira no Século 21}

Neste estudo de caso, nosso objetivo é analisar o emprego de valores meritocráticos na reascensão de ideologias e governos de extrema direita no Brasil. Como pilar fundante das práticas capitalistas e neoliberais, o discurso meritocrático fez parte do ataque estruturado e organizado das elites brasileiras à esquerda, em especial aquelas no poder na época e associadas ao PT (Partido dos Trabalhadores), em uma transparente e exitosa tentativa de retomar o controle do país. Fundamentados no princípio marxista de que a dominação de classe é material e ideológica (Marx; Engels, 1968), abordamos a meritocracia como parte da estrutura ideológica dominante e como justificativa para as desigualdades sistêmicas e ontológicas do capitalismo.

O Estado de bem-estar pós-neoliberal promovido pelos governos do PT fomentou transformações no estilo de vida das classes trabalhadoras brasileiras e desencadeou um processo de mobilidade estrutural ${ }^{3}$ no país. Ambos os presidentes promoveram políticas públicas para aliviar a pobreza, acelerar a participação social de grupos historicamente oprimidos e garantir direitos para as esferas esquecidas das classes trabalhadoras (Belluzzo, 2013).

Entre as elites e a classe média alta, a melhoria geral das condições de vida das classes trabalhadoras cria uma atmosfera de ameaça aos seus privilégios. É a ameaça ao status quo que leva as elites a apoiarem um político de extrema direita e desconhecido pela maioria da população do país até meados dos anos $2000^{4}$.

Das sombras da mediocridade, Jair Bolsonaro surgiu como salvador da sociedade para lutar pela moralidade, pela propriedade privada, pela família tradicional patriarcal e pela ordem militar. Para a burguesia, ele foi o caminho para retirar o poder das mãos do Partido dos Tra- 
Capitalismo, Classe e Meritocracia

balhadores. Para a classe média ${ }^{5}$ e para a classe trabalhadora do setor primário $^{6}$, ele foi o homem que falou por aqueles que se sentiam injustiçados e privados de seus privilégios ${ }^{7}$. Quanto à classe trabalhadora do setor secundário, “[...] [e]m tempos de democracia formal 'tranquila', o trabalhador industrial tem, em princípio, duas possibilidades abertas para ele: a identificação com a classe média acima dele, ou a identificação com a sua própria posição social [...]” (Reich, 1946, p. 40). Entra em jogo o papel da manipulação da realidade.

O controle dos meios de comunicação possibilitou a articulação de três elementos principais para reescrever a realidade e promover uma nova compreensão do cenário político brasileiro, a saber (1) a imagem do PT como o único e mais corrupto partido político de todos os tempos ${ }^{8}$, (2) a defesa do Estado laico como imoral contra os princípios cristãos $^{9} /{ }^{10}$, com o apoio das Igrejas Pentecostais e Evangélicas (Leher, 2019), e (3) a associação de programas sociais e ações afirmativas para alívio da pobreza e promoção da inclusão social com a injustiça social $^{11 / 12}$. Essas três estratégias discursivas podem ser resumidas como (1) o discurso contra a corrupção; (2) a defesa em favor da moral fundada no Cristianismo; e (3) os princípios da meritocracia.

A articulação desses três elementos (i) estabeleceu com sucesso uma narrativa com dois personagens antagônicos - a direita (nós) contra a esquerda (eles) ${ }^{13}-$, (ii) deslocou os problemas históricos e estruturais engendrados no seio da sociedade brasileira para o nível individual, (iii) cooptou a classe trabalhadora de volta aos princípios ideológicos da elite e das classes altas e (iv) impingiu na sociedade brasileira a necessidade urgente de derrubar o PT e salvar o país das mãos do comunismo ${ }^{14}$. Nesse cenário polarizado, tudo o que divergisse das ideias do novo Crapulisnky ${ }^{15}$ era "[...] imediatamente punido como um 'ataque à sociedade', e [...] marcado como 'Socialismo'” (Marx, 1977, p. 25).

Esses elementos são importantes porque a análise da meritocracia no Brasil pressupõe a dissecação dos papéis desempenhados pelas classes médias na ascensão da extrema-direita brasileira (Cavalcante, 2018; Souza, 2018). A classe média se alimenta das migalhas dos privilégios das elites dominantes e luta para preservá-los. Ela historicamente ocupa um papel de destaque a favor da classe dominante e de seu sistema ideológico em períodos de transformação na estrutura de classes do país (Fernandes, 2019).

Williams, em sua análise das relações entre indivíduos e sociedades, considera esse estrato social de conservação no conceito de servo (Williams, 2011, p. 112-113). O servo deseja pertencer, e enganosamente pensa que pertence, a um sistema que não é seu. O servo pode ser contrastado, no mesmo estrato social, com os subjugados - aqueles que não se consideram parte dessa formação social particular, mas não têm outra opção - e, em um nível superior, com os membros - aqueles que diretamente ou indiretamente dominam as relações e instituições sociais e desfrutam de todos os direitos e produtos dessa sociedade. O escrutínio da figura do servo no capitalismo revela semelhanças com o indivíduo de classe média no Brasil. Williams (2011, p. 112, grifo nosso) indica que ao servo 
[...] é dada a ilusão de escolha e ele é convidado a se identificar com o modo de vida que lhe é oferecido. É uma ilusão de escolha, porque, assim como o subjugado, ele não tem uma maneira óbvia de manter sua vida ao se opor. No entanto, a ilusão é importante, pois lhe permite fingir uma identificação com a sociedade, como se a escolha tivesse sido real. [...] Ele pode até, conscientemente, pensar a si mesmo como um membro [...].

Enganado pela ideia de ser membro, o servo acredita estar se distanciando de uma massa de trabalhadores e se aproximando do estilo de vida almejado, o da elite. É esse movimento ilusório que caracteriza a classe média-alta brasileira como esfera de conservação e seu apoio inquestionável às elites.

É interessante notar que ao mesmo tempo em que as políticas de assistência social pareciam melhorar as condições gerais de vida da população em todas as esferas sociais, a narrativa criada para derrubar o PT absorveu as classes trabalhadoras e estimulou a crença no mito do Nova Classe Média, formada por aqueles que enganosamente se viram mais próximos dos privilégios materiais da classe média alta e da elite devido exclusivamente ao seu próprio mérito (Chauí, 2013b; 2016; Pochmann, 2014). O discurso meritocrático conseguiu associar a expansão do consumismo e a melhoria geral de vida da população ao mérito, ao mesmo tempo em que "[...] expressava aversão ao privilégio arraigado, principalmente se fosse promovido pelo 'Estado'” (Littler, 2018a, p. 81). Como concluíram McNamee e Miller (2009), em uma sociedade fundada na ideologia da meritocracia, qualquer forma de política pública para acelerar a inclusão social é desprezada.

O mito da Nova Classe Média reproduz a falácia da mobilidade de classe e atribui ao indivíduo o mérito pelo sucesso ou a culpa pelo fracasso. No entanto, existem contradições no conceito que revelam a realidade da divisão social do trabalho e a necessidade de um estrato social se diferenciar dos trabalhadores menos qualificados e da cultura comum e popular (McNamee; Miller, 2009; Pachukanis, 2020). A urgência de criar e pertencer a uma nova classe média expõe a obsessão de se aproximar de uma forma de vida elitista e se afastar da classe trabalhadora. As principais formas de distinção social são traduzidas como símbolos meritocráticos e ocorrem na

[...] busca de prestígio e dos signos de prestígio, como os diplomas e títulos vindos das profissões liberais, e pelo consumo de servicos e objetos indicadores de autoridade, riqueza, abundância, ascensão social, [por exemplo], a casa no 'bairro nobre' com quatro suítes, o carro importado, a roupa de marca etc. Em outras palavras, o consumo lhe aparece [à classe média] como ascensão social em direção à classe dominante e como distância intransponível entre ela e a classe trabalhadora (Chauí, 2013a, p. 132).

No Brasil, a mobilidade estrutural viabilizada na primeira década do século 21 ampliou o acesso a esses signos de prestígio. Este acesso, 
Capitalismo, Classe e Meritocracia

no entanto, foi ressignificado como resultado do mérito individual e não como resultado da influência direta de políticas públicas. Em poder de símbolos que reproduziam prestígio social, as classes trabalhadoras foram seduzidas e cooptadas pela meritocracia. Afinal,

[...] a distância entre o proprietário de um fusca da Volkswagen e o proprietário de uma Mercedes era bem menor do que a distância entre o proprietário de qualquer carro e o proprietário de nenhum carro, especialmente se os carros mais caros estivessem (em teoria) disponíveis em prestações mensais (Hobsbawm, 1995, p. 307).

O Brasil como um todo testemunhou o surgimento de um movimento ideológico de apoio massivo à extrema-direita atraído pela elite e pela classe média alta, principalmente após as eleições de 2014 (Cavalcante, 2018); situação semelhante à observada por Hobsbawm (1995) nas sociedades de capitalismo avançado nas décadas de 1970 e 1980.

Os movimentos contra as ações afirmativas e outras políticas públicas que promoveriam a mobilidade estrutural foram liderados por aqueles que se consideravam "[...] mais qualificados e mais respeitáveis" (Hobsbawm, 1995, p. 302) e que viam a mobilidade estrutural como uma forma de invasão bárbara aos espaços que pertenciam exclusivamente aos estratos superiores, numa associação de elitismo e meritocracia. Os principais argumentos contra elas foram (1) discriminação reversa, ou seja, discriminação contra a classe média branca; (2) a injustiça com os candidatos mais qualificados que se candidatam ao mesmo emprego ou curso universitário; e (3) ação afirmativa como antidemocrática. Esses argumentos ganharam maior adesão popular durante a ascensão de Jair Bolsonaro na mídia, que afirmou inúmeras vezes que não entraria em um avião pilotado por um cotista nem faria uma cirurgia realizada por um cotista porque isso significaria que não haviam sido contratados porque eram capazes de fazer o trabalho, mas apenas por $\operatorname{cota}^{16}$.

McNamee e Miller (2009, p. 43) apontam que “[...] [o]s defensores da meritocracia (e os críticos das ações afirmativas) muitas vezes proclamam que a questão de 'quem deve obter o que' é simples e direta: basta contratar a pessoa mais qualificada para o trabalho"17. O que os defensores da meritocracia não entendem - ou simplesmente ignoram - é que o mérito individual esconde privilégios arraigados que eles supostamente odeiam (McNamee; Miller, 2009).

A “[...] alegação de que a ação afirmativa é antimeritocrática, de que ela equivale à discriminação reversa, e de que levou à contratação e promoção de milhares de minorias (negros) em vez de homens brancos mais qualificados [...]" (McNamee; Miller, 2009, p. 207) logo se tornou o lema daqueles que posicionam contrários às cotas ${ }^{18}$. Bolsonaro, por exemplo, ainda candidato à presidência afirmou que "[...] [i]sso tudo é uma maneira de dividir a sociedade. [...] Isso não pode continuar existindo, tudo é coitadismo. Coitado do negro, coitada da mulher, coitado do gay, coitado do nordestino, coitado do piauiense. Tudo é coitadismo no Brasil. Vamos acabar com isso"19 
Wayne; Cabral

Seduzidas pela falácia de sua ascensão social meritocrática, as classes trabalhadoras incorporaram o discurso da moral e da anticorrupção da elite brasileira. A nova classe trabalhadora apoiou o projeto de um governo populista de extrema direita que busca desmantelar políticas de combate à desigualdade social, priorizar a formação técnica da classe trabalhadora e intensificar a ideologia da competência e da meritocracia, por meio do "[...] estímulo ao individualismo competitivo agressivo e ao sucesso a qualquer preço por meio da astúcia, para operar com os procedimentos do mercado" (Chauí, 2016, p. 20).

O individualismo competitivo é o eco social das instituições ideológicas meritocráticas americanas que são cultuadas por brasileiros de classe média com um complexo de vira-lata. A meritocracia americana, moldada com base no cristianismo capitalista, é o fundamento ideológico hegemônico perfeito para um país com um dos mais altos níveis de desigualdade social do mundo ${ }^{20}$. Ignorando quaisquer efeitos produzidos por herança, relações sociais (conexões), sorte, discriminação, casamento, mobilidade intergeracional, (McNamee; Miller, 2009) e atividade criminosa (sucesso a qualquer preço, como Chauí aponta), a meritocracia apoia a ideia de que a posição social é um resultado direto do esforço e do talento individual. Seja no topo ou na base, as pessoas ocupam o espaço social e geográfico que merecem, de acordo com seu talento individual e o esforço que colocaram no sistema. A meritocracia é a obsessão em supervalorizar os processos de individualização e os símbolos do esforço individual ilusório. A adesão a esses princípios ideológicos permite ao indivíduo aproximar-se de um estilo de vida desejado e afastar-se do pesadelo de pertencer à classe trabalhadora (Chauí, 2013a; 2013b). Desconhecemos uma descrição mais precisa das crenças ideológicas da classe média brasileira.

A ideia de uma formação acrítica e técnica para a classe trabalhadora ao invés de títulos universitários entra no discurso do senso comum hegemônico como uma forma descomplicada e garantida de acesso ao mercado de trabalho. Segundo o ex-ministro da Educação, Abraham Weintraub,

A escola pode ensinar um ofício. Aí vem o preconceito desses 'intelectualóides' que acham que escola técnica não é boa porque ensina ofício. Tem que ser doutor. Está cheio de doutor sem emprego, mas é difícil ter um bom encanador passando fome ou na fila do Bolsa Família. É difícil um eletricista, um técnico bom, que não consegue se virar ${ }^{21}$.

Observe que a questão não é ser a favor ou contra a educação técnica, mas indicar as contradições em suas entranhas. A contradição quintessencial da educação técnica é a manutenção de uma escola privada de alto nível para a elite e a promoção da formação técnica básica para a classe trabalhadora. Em uma sociedade fundada na meritocracia, "[...] a educação [supostamente] identifica e seleciona indivíduos inteligentes, talentosos e motivados e oferece treinamento educacional em proporção direta ao mérito individual" (McNamee; Miller, 2009, p. 107), em vez 
Capitalismo, Classe e Meritocracia

disso, a educação dentro desses princípios tende a reproduzir a desigualdade social. Em outras palavras, dentro dos limites estruturais do capital, a lógica de acesso àquela forma particular de educação reproduz as mesmas condições de classe que as criaram, sem possibilidade de alteração do sistema operacional. A preservação da meritocracia em uma sociedade que oferece processos de escolarização diferenciados para a elite, para as classes médias e para as camadas mais pobres da população só pode se sustentar como forma de reproduzir a desigualdade social, explorando os pobres e mantendo a elite de 1\% (Zizek, 2012) que domina todo o resto.

Em termos de educação, a meritocracia se consolidou como um discurso hegemônico fundamental na reprodução de uma escola de classe média que imita as cores, a estrutura física, os símbolos, a estrutura organizacional e os ideais das escolas de elite. No entanto, uma comparação entre as mensalidades ilustra de forma simples como as escolas privadas para a classe média são apenas cópias das escolas de elite. Enquanto a mensalidade média de uma escola de elite em São Paulo é de R\$11.833 (R\$ 142.000 por ano), as mensalidades das escolas particulares de classe média giram em torno de $\mathrm{R} \$ 815,65$ por mês ( $\mathrm{R} \$$ 9.787,80 por ano). Apesar das tentativas de reproduzir a educação elitista, as escolas de classe média buscam o maior número possível de alunos aprovados em vestibulares, enquanto as escolas de elite visam oferecer uma educação holística para alunos que geralmente não estão preocupados com a ideia de entrar ou não na universidade, em vez disso, eles precisam ser educados para estarem prontos para ocupar seu lugar no topo da hierarquia social. No caso da classe média, a obsessão com os vestibulares ${ }^{22}$ se justifica pela necessidade de dominar os símbolos de prestígio (Chauí, 2016; Pochmann, 2013).

Privada do acesso a qualquer uma dessas opções, às classes trabalhadoras das camadas sociais mais baixas é oferecida uma educação técnica e militar. A militarização das escolas facilita a aceitação da hierarquia, permite a incorporação ideológica do sucesso pelo mérito e domestica uma classe não revolucionária, obediente e explorável. $\mathrm{O}$ acesso à educação pública, à educação privada de classe média e à educação de elite é a forma essencial de reproduzir as práticas, símbolos, signos e significados das condições de classe. Porém, assim como Williams (1989, p. 14), “[...] não posso aceitar que a educação seja uma formação para o trabalho ou uma formação de cidadãos úteis (isto é, que se enquadrem neste sistema)" para a classe trabalhadora e uma forma de educação completamente diferente para a elite.

O discurso hegemônico meritocrático disseminado nas escolas e imposto aos alunos, cada um de acordo com sua classe, não apenas reproduz as condições de classe social, mas também possibilita o sentimento de conformidade com o status quo. Sem acesso à educação crítica, a classe trabalhadora - incluindo a classe média - tende a adotar os fundamentos ideológicos da elite como seus e a se conformar à ordem estabelecida. 


\section{Considerações Finais}

Discutindo a estrutura ideológica do conceito de alienação de Marx, Mészáros argumenta que faz parte do papel da educação reproduzir com sucesso indivíduos que cumpram a estrutura de valores da sociedade. Assim, indivíduos “[...] cujos 'próprios fins' não negam as potencialidades do sistema de produção vigente" (Mészáros, 1970, p. 289). Anos depois, Williams (1980) também aponta que os processos de incorporação promovidos pelas instituições educacionais formais e informais são cruciais para a manutenção dos valores, práticas, significados e símbolos hegemônicos capitalistas.

A ideologia meritocrática faz com que as pessoas pensem que são as únicas responsáveis pelos destinos de suas vidas. Aqueles que ocupam uma posição de prestígio na sociedade progrediram e, portanto, merecem estar lá. Em contraste, aqueles que ainda estão lutando carecem de impulso ou talento para ter sucesso. Cooptada pela estrutura meritocrática do capital, a classe trabalhadora se junta à resistência contra as possibilidades de mudança (Williams, 1989).

Nossas análises apontam para o que podemos chamar de uma estrutura de valores, práticas, significados e símbolos meritocráticos. A meritocracia funciona como um pilar ideológico da hegemonia do capitalismo e uma justificativa para as desigualdades que engendra. Apesar das diferenças históricas e culturais entre o Reino Unido e o Brasil, as classes médias são identificadas como elementos-chave na reprodução dessa estrutura meritocrática de símbolos materiais e culturais: uma preferência por sotaques que emulam as elites e a associação do consumismo com mobilidade social e sucesso. Elas vivem no reino das redes de segurança, mas supostamente promovem práticas de risco; criticam as políticas governamentais para acelerar a participação social, mas não conseguem perceber como se beneficiam delas; pensam que estão no topo, mas apenas imitam o estilo de vida das elites. Além disso, em ambos os países, a educação privada cimenta discrepâncias sociais, materiais e culturais entre as classes ao restringir o acesso a carreiras dominadas pela elite.

A educação está envolvida na “[...] construção e na reconstrução contínua de uma cultura dominante efetiva” (Williams, 1980, p. 39), mas é também nas práticas educacionais que podemos promover uma compreensão crítica da realidade, de consciência de classe e consciência das atividades hegemônicas estruturais do capital. Isso é de importância fundamental, principalmente em períodos de democracia formal tranquila, como aponta Reich (1946, p. 40), quando os trabalhadores devem decidir seguir a elite ou se filiarem ao seu próprio status social. 


\section{Notas}

1 Informações disponíveis em: <http://www.theactingclass.info>.

2 Leaky pipeline poderia ser traduzido como vazamento na/da tubulação e tem sido incorporado pela literatura em Língua Portuguesa como afunilamento, para indicar a baixa representatividade de grupos sociais em determinadas áreas.

3 A mobilidade estrutural, em contraste com a mobilidade social, é a melhoria geral das condições de vida da população como um todo (McNamee; Miller, 2009).

4 Ver: Pachukanis (2020) para uma análise aprofundada da relação entre o fascismo e a burguesia.

5 Classe média no singular pode ser usado para caracterizar os $2 \%$ da população brasileira que pertence à classe média alta, uma classe que foi fundada nos princípios do autoritarismo, militarismo, elitismo, racismo, moralismo e meritocracia (Souza, 2018; Pochmann, 2014). Estamos cientes das contradições engendradas pelo conceito de classe média na tradição marxista, porém, devido ao espaço limitado, não entraremos na discussão epistemológica do conceito. Para uma discussão mais aprofundada, considere os trabalhos de Erik O. Wright, para uma análise internacional, e de Márcio Pochmann, Marilena Chauí e Sávio Cavalcante, para o contexto brasileiro.

6 Os empregos do setor primário e secundário representam respectivamente "[...] aqueles com altos salários, altos níveis de qualificação, boas condições de trabalho, segurança no emprego e amplas oportunidades de promoção" em contraste com "[...] baixos salários, baixos níveis de qualificação, más condições de trabalho, pouca segurança no emprego e poucas ou nenhumas possibilidades de avanço" do segundo setor (Barnes, 1992, p. 57).

7 Eleitor típico de Bolsonaro é homem branco, de classe média e superior completo. Disponível em: <https://www.cartacapital.com.br/politica/eleitor-tipico-debolsonaro-e-homem-branco-de-classe-media-e-superior-completo/>. Acesso em: jan. 2021.

8 Pesquisa:PTéa Sigla com mais Corruptos, 13 mar. 2007. Disponível em: <http:// g1.globo.com/Noticias/Politica/0,,AA1486307-5601,00.html>. Acesso em: jan. 2021.

9 Carta de Haddad aos evangélicos esconde apoio do PT ao aborto, ao "kit gay' è ideologia de gênero, 18/10/2018. Retrieved from: <https://www.gazetadopovo. com.br/ideias/carta-de-haddad-aos-evangelicos-esconde-apoio-do-pt-aoaborto-ao-kit-gay-e-a-ideologia-de-genero-8vyiex9yjqadg7s3gy4rsdi7l/>. Acesso em: jan. 2021.

10 As ameaças contra acadêmicos, jornalistas e políticos no Brasil têm nome: bolsoterrorismo 21 jan. 2021. Disponível em: <https://theintercept.com/2021/01/21/ as-ameacas-contra-academicos-brasileiros-tem-um-nome-no-brasil-bolsoterrorismo/>. Acesso em: jan. 2021.

11 De crítico a defensor do Bolsa Família: veja frases de Bolsonaro 27 ago. 2020 Disponível em: <https: // www. agazeta.com.br/es/politica/de-critico-a-defensor-do-bolsa-familia-veja-frases-de-bolsonaro-0820>. Acesso em:jan. 2021.

12 Antes de ampliar Bolsa Família, Bolsonaro defendeu fim do benefício, 17 out. 2019. Disponível em: <https://noticias.uol.com.br/politica/ultimas-noti- 
cias/2019/10/17/antes-de-ampliar-bolsa-familia-bolsonaro-defendeu-fim-dobeneficio.htm?>. Acesso em: jan. 2021.

13 A direita brasileira que saiu do armário não para de vender livros, 01 ago. 2015. Disponível em: <https://brasil.elpais.com/brasil/2015/07/22/politica/1437521284_073825.html>. Acesso em: jan. 2021.

14 Dado que nosso objetivo não é analisar a estrutura ideológica dos governos Lula e Dilma, recomendamos os trabalhos em Sader et al. (2013).

15 No 18 de Brumário de Luís Bonaparte, Marx (1977) chama Louis Bonaparte de Crapulinsky, nome que deriva da palavra francesa crapule, um patife, um vigarista, um crápula.

16 Disponível em: <https://politica.estadao.com.br/noticias/geral,as-frasespolemicas-de-jair-bolsonaro, 1127819>. Acesso em: jan. 2021.

17 Veja os argumentos de Bolsonaro em: <https://www.youtube.com/ watch?v=AqzUopE1l8k >. Acesso em: jan. 2021.

18 Disponível em: <http://gl.globo.com/jornal-nacional/noticia/2014/11/ declaracoes-de-professor-contrario-ao-regime-de-cotas-provoca-indignacao. html>. Acesso em: jan. 2021.

19 Disponível em: <https://gl.globo.com/politica/eleicoes/2018/noticia/2018/10/24/bolsonaro-diz-ser-contra-cotas-e-que-politica-de-combateao-preconceito-e-coitadismo.ghtml>. Acesso em: jan. 2021.

20 Dados do Instituto Brasileiro de Geografia e Estatística (IBGE) indicam concentração de $43,1 \%$ da renda do país nas mãos de apenas $10 \%$ da população. Em 2018, o 1\% mais rico da população ganhava o equivalente a 34 vezes mais que a metade com menor nível de renda.

21 Disponível em: <https://gazetaweb.globo.com/portal/noticia/2019/10/ weintraub-diz-que-e-dificil-encanador-passar-fome-ao-defender-ensinotecnico_87573.php>. Acesso em: jan. 2021.

22 Esses elementos podem ser percebidos nas entrevistas dos pais em duas fontes diferentes: <https://noticias.uol.com.br/colunas/paulo-sampaio/2020/07/12/ escola-cobra-12-mil-por-mes-e- nao-da-aula-on-line-na-quarentena-dizempais.htm> e <https://www.acidadeon.com/cotidiano/brasil-e-mundo/NOT, 0,0,1515630, Demissoes $+\mathrm{e}+$ reducao $+\mathrm{de}+$ salario + levam + pais $+\mathrm{a}+$ trocar + filhos + de + escola + na + pandemia.aspx>. Acesso em: nov. 2020.

\section{Referências}

BANKS, Mark; HESMONDHALGH, David. Looking for Work in Creative Industries Policy. International Journal of Cultural Policy, v. 15, n. 4, p. 415-430, 2009. BARNES, Colin. Deficiência e Emprego. Personnel Review, MCB University Press, v. 21, n. 6, p. 55-73, 1992.

BELFIORE, Eleonora. On Bullshit in Cultural Policy Practice and Research: notes from the british case. International Journal of Cultural Policy, v. 15, n. 3, p. 343-359, 2009.

BELLUZZO, Luiz Gonzaga. Os Anos do Povo. In: SADER, Emir (Org.). Lula e Dilma: 10 anos de governos pós-neoliberais no Brasil. São Paulo: Boitempo, 2013. P. $103-110$. 
BLACKBURN, Robin. The Corbyn Project. New Left Review, May/June 2018.

BLAIR, Helen. 'You're Only as Good as Your Last Job': the labour process and labour market in the british film industry. Work, Employment \& Society, v. 15, n. 1, p. 149-169, 2001.

BLAIR, Tony. 'Britain Is on a Roll Whatever the Pop Stars Say'. In: OAKLAND, John (Ed.). Contemporary Britain, a Survey with Texts. London: Routledge, 2001.

BOLTANSKI, Luc; CHIAPELLO, Eve. The New Spirit of Capitalism. London: Verso, 2018.

BOURDIEU, Pierre. Pascalian Meditations. Translated by Richard Nice. Cambridge: Polity Press, 2000.

CAVALCANTE, Sávio. Classe Média, Meritocracia e Corrupção. Crítica Marxista, n. 46, p. 103-125, 2018.

CHAUÍ, Marilena. Manifestações Ideológicas do Autoritarismo Brasileiro. Belo Horizonte: Autêntica Editora, 2013a.

CHAUÍ, Marilena. Uma Nova Classe Trabalhadora. In: SADER, Emir (Org.). Lula e Dilma: 10 anos de governos pós-neoliberais no Brasil. São Paulo: Boitempo, 2013b. P. 123-134

CHAUÍ, Marilena. A Ideologia da Competência. Belo Horizonte: Autêntica Editora, 2016.

FERNANDES, Florestan. Apontamentos sobre a 'Teoria do Autoritarismo'. São Paulo: Expressão Popular, 2019.

FRIEDMAN, Sam; LAURISON, Daniel. The Class Ceiling. Why it pays to be privileged. Bristol: Policy Press, 2019.

FRIEDMAN, Sam; O'BRIEN, Dave; LAURISON, Daniel. 'Like Skydiving without a Parachute': how class origin shapes occupational trajectories in british acting. Sociology, v. 51, n. 5, p. 992-1010, 2017.

HARVEY, David. A Brief History of Neoliberalism. New York: Oxford University Press, 2005.

HOBSBAWM, Eric. Era dos Extremos: o breve século XX. São Paulo: Companhia das Letras, 1995.

KIRBY, Philip. Leading People 2016. The educational backgrounds of the UK professional elite. Londres: The Sutton Trust, 2016.

LABOUR PARTY. Acting Up Report, Labour's Inquiry into Access and Diversity in the Performing Arts. 2017.

LEHER, Roberto. Apontamentos Para Análise da Correlação de Forças na Educação Brasileira: em prol da frente democrática. Educação \& Sociedade, Campinas, v. 40, p. 1-18, 2019.

LITTLER, Jo. Against Meritocracy: culture, power and myths of mobility. Oxon; New York: Routledge, 2018a.

LITTLER, Jo. Young and Old Meritocracy: from radical critique to neoliberal tool. Renewal: a journal of social democracy, v. 26, n. 1, p. 40-51, 2018 b.

MARX, Karl. The Eighteenth Brumaire of Louis Bonaparte. New York: International Publishers, 1977.

MARX, Karl; ENGELS, Friedrich. The German Ideology. Moscow: Progress Publishers, 1968 .

MCGUIGAN, Jim. Cool Capitalism. London: Pluto Press, 2009. 
MCGUIGAN, Jim. 'Creative Labour, Cultural Work and Individualisation'. International Journal of Cultural Policy, v. 16, n. 3, p. 323-335, 2010.

MCNAMEE, Stephen; MILLER, Robert. The Meritocracy Myth. Lanham; Maryland: Rowman \& Littlefield Publishers Inc., 2009.

MCROBBIE, Angela. Rethinking Creative Economy as Radical Social Enterprise. Variant, n. 41, p. 32-33, 2011.

MÉSZÁROS, István. Marx's Theory of Alienation. London: Merlin Press, 1970.

MILLER, Toby. 'From Creative to Cultural Industries'. Cultural Studies, v. 23, n. 1, p. 88-99, 2009.

NEELANDS, Jonothan. Enriching Britain: culture, creativity and growth. Coventry: University of Warwick, 2015.

NEWSINGER, Jack. 'A Cultural Shock Doctrine? Austerity, the neoliberal state and the creative industries discourse' Media, Culture \& Society, v. 37, n. 2, p. 302-313, 2015.

O'BRIEN, Dave; LAURISON, Daniel; MILES, Andrew; FRIEDMAN, Sam. Are the creative industries meritocratic? An analysis of the 2014 British Labour Force Survey. Cultural Trends, v. 25, n. 2, p. 116-131, 2016.

OAKLEY, Kate. In Its Own Image: New Labour and the cultural workforce, Cultural Trends, v. 20, n. 3-4, p. 281-289, 2011.

PACHUKANIS, Evgeni. Fascismo. São Paulo: Boitempo, 2020.

POCHMANN, Marcio. Políticas Públicas e Situação Social na Primeira Década do Século XXI. In: SADER, Emir (Org.). Lula e Dilma: 10 anos de governos pósneoliberais no Brasil. São Paulo: Boitempo, 2013. P. 145-156.

POCHMANN, Marcio. O Mito da Grande Classe Média: capitalismo e estrutura social. São Paulo: Boitempo, 2014.

RAMASWAMY, Chitra. Welcome to the Dragon School - the lair of the British acting elite. The Guardian, March 28th, 2016. Available at: <https://www.theguardian.com/education/shortcuts/2016/mar/28/dragon-school-tom-hiddleston-tom-hollander-hugh-laurie-night-manager>. Accessed on: 10th Feb. 2021.

RANDLE, Keith; WING-FAI, Leung; KURIAN, Juno. Creating Difference, Overcoming Barriers to Diversity in UK Film and Television Employment. Hertfordshire: Creative Industries Research and Consultancy Unit; University of Hertfordshire; Skillset/UK Film Council, 2008.

REICH, Wilhelm. The Mass Psychology of Fascism. New York: Orgone Institute Press, 1946.

ROSS, Andrew. Nice Work If You Can Get It: life and labor in precarious times. New York: New York University Press, 2010.

SOUZA, Jessé. A Classe Média no Espelho: sua história, seus sonhos e ilusões, sua realidade. Rio de Janeiro: Estação Brasil, 2018.

THE ACTING class. Direction: Deirdre O'Neill e Mike Wayne. Production: Deirdre O'Neill e Mike Wayne. Casting: Tom Stocks, Andrew Ellis, Julie Hesmondhalgh, Christopher Eccleston, Maxine Peake, Samuel West. UK, 2017. 1 DVD (77 min.)

WAYNE, Mike. Working Title Mark II: a critique of the Atlanticist paradigm for British cinema. International Journal of Media and Cultural Politics, v. 2, n. 1, p. 59-73, 2006. 
WAYNE, Mike. England's Discontents, Political Cultures and National Markets. London: Pluto Press, 2018.

WILLIAMS, Raymond. Problems in Materialism and Culture: selected essays. London; New York: Verso, 1980.

WILLIAMS, Raymond. Resources of Hope: culture, democracy, socialism. London; New York: Verso, 1989.

WILLIAMS, Raymond. The Long Revolution. Cardigan: Parthian, 2011.

ZIZEK, Slavoj. O Violento Silêncio de um Novo Começo. In: HARVEY, David et al. Occupy: movimentos de protesto que tomaram as ruas. São Paulo: Boitempo Editorial: Carta Maior, 2012. P. 15-26.

Michael Wayne possui doutorado pela Escola de Arte, Design e Artes Cênicas da Middlesex University (1999). Atualmente é professor de Screen Media na Brunel University. Seus principais focos de pesquisa são: cinema popular e tradições do cinema político alternativo (especialmente o Terceiro Cinema) e estudos de mídia e produção cinematográfica. Aborda o cinema e os estudos de mídia a partir das ricas e complexas bases teórico-metodológicas do marxismo.

ORCID: https://orcid.org/0000-0002-1285-5976

E-mail:michael.wayne@brunel.ac.uk

Vinícius Neves de Cabral é doutor em Educação pela Universidade Estadual de Londrina (UEL). É pesquisador associado ao Centro de Estudos Críticos e Pesquisa em Educação e Desigualdade Social (UEL), é membro do Conselho Editorial da Journal for Critical Education Policy Studies (JCEPS) e da Journal of Class and Culture. Investiga as relações entre o campo da educação, da cultura e da análise cultural, com base em metodologias marxistas. ORCID: https://orcid.org/0000-0002-4632-3708

E-mail:mad.vinny@hotmail.com

Editora-responsável: Carla Vasques

Este é um artigo de acesso aberto distribuído sob os termos de uma Licença Creative Commons Atribuição 4.0 Internacional. Disponível em: <http:// creativecommons.org/licenses/by/4.0>. 